\title{
MODALITY OF DETERMINING THE RISK SCORES AND THEIR RANKING FOR THE DIRECT ACQUISITION MADE IN SEAP
}

\author{
Cristiana Daniela LAZĂR *, Andreea Mihaela MARIN **, Ion PEREŞ * \\ * The West University, Timişoara, Romania \\ ** „Eftimie Murgu” University Reşiţa, Romania \\ cristianamun@yahoo.com, andreeamarinmihaela@yahoo.com
}

\begin{abstract}
In order to shape a representative economic model, meant to be used for the analysis of direct acquisitions conducted by the public institutions on the electronic platform called SEAP (Electronic System of Public Acquisitions) we need to make a series of calculations which can lead to the establishment of risk scores for this types of acquisitions or procurements and their ranking, This hierarchy shall provide the public institutions with valuable items of information for the awareness of direct acquisitions particularities.
\end{abstract}

\section{Keywords: SEAP, direct acquisition, risk, public institution}

\section{Determining the risk score}

The Electronic System of Public Acquisitions (Romanian acronym SEAP) is in fact the "legal procurement market” for all the public institutions in Romania. Like any other market, SEAP is governed also by the law of demand and supply; it is the virtual place where purchasers of products / services / works (namely the state's institutions) meet the economic operators, more precisely the offering firms. In SEAP there is competition, but there are risks too, which may be manifest or not, which may have economic consequences or not. That is why, in the conditions of practising a modern management, any state institution should study both the possible risks threatening the institution, and the possibility of materialising these negative economic consequences which may be transposed into pecuniary losses. From the logic-statistic standpoint, the materialisation of economic consequences of a certain risk will occur only after the risk occurs and manifests itself.

For instance in a hospital (public institution), the risks specific to their direct acquisition in SEAP, more frequently encountered, may be synthesised in the table no. 1 below:

Table 1 Determining the probabilities of risks occurrence and effect (source: author's conception and processing)

\begin{tabular}{|c|l|c|c|c|c|c|}
\hline No. & \multicolumn{1}{|c|}{ Risk definition } & Symbol & $N_{a_{i}}$ & $P_{s m_{i}}$ & $V_{e_{i}}$ & $P_{s e_{i}}$ \\
\hline 1. & $\begin{array}{l}\text { Writing down } \\
\text { inaccurate data in the } \\
\text { necessary report }\end{array}$ & $R_{1}$ & 10 & 0.123 & 738.81 & 0.177 \\
\hline 2. & $\begin{array}{l}\text { Unreal character of the } \\
\text { stocks displayed in } \\
\text { SEAP }\end{array}$ & $R_{2}$ & 32 & 0.395 & 1638.59 & 0.393 \\
\hline
\end{tabular}




\begin{tabular}{|c|l|c|c|c|c|c|}
\hline 3. & $\begin{array}{l}\text { Relatively low price of } \\
\text { product doubled by a } \\
\text { small quantitative } \\
\text { demand }\end{array}$ & $R_{3}$ & 15 & 0.185 & 919.00 & 0.220 \\
\hline 4. & $\begin{array}{l}\text { Conditioning the } \\
\text { purchase on the } \\
\text { acquisition of a } \\
\text { minimum imposed } \\
\text { quantity }\end{array}$ & $R_{4}$ & 24 & 0.297 & 876.56 & 0.210 \\
\hline \multicolumn{1}{|c|}{ TOTAL } & 81 & 1.000 & 4172.96 & 1.000 \\
\hline
\end{tabular}

where:

identification and analysis charts $N_{a_{i}}$ - total number of occurrences of causes of the "i"-type risk;

$P_{s m_{i}}$ - statistic-mathematic probability of occurrence of causes generating “i”-type risks;

$V_{e_{i}}$ - value of economic materialisation of the "i"-type risk;

$P_{s e_{i}}$ - statistic-economic probability of manifestation of the " $i$ "-type risk;

$V_{e_{i}}$ - value of economic materialisation of the "i"-type risk;

$V_{t}$ - total value of all risks materialisation.

We point out that the numerical results in table no. 1 are obtained from previous calculations based on the centralisation of the data supplied by the problem

(Romanian acronym FIAPs), which were elaborated during an audit mission.

We must keep in mind that a general calculation formula of total risk score is:

$T_{i}=\operatorname{Pr}_{(r i)} I_{(r i)}$, where:

$\mathrm{T}_{\mathrm{i}}$ - total score of " $\mathrm{i}$ " risk;

$\operatorname{Pr}_{(\mathrm{ri})}$ - Manifestation probability of " $\mathrm{i}$ " risk;

$I_{(\mathrm{ri})}$-impact of "i" risk (its economic consequence).

Taking into consideration all the above and the results in table no. 1, the total risk score could be calculated with a formula of the type :

$T_{i}=\operatorname{Psm}_{i} V e_{i}$

In these circumstances, the calculation of total risk score for the 4 risks identified in the hospital is elaborated and presented in the following table:

Table 2 Calculation of total risk scores (source: author's conception and processing)

\begin{tabular}{|c|c|c|c|c|}
\hline No. & Symbol & $P_{s m_{i}}$ & $V_{e_{i}}$ & $\begin{array}{c}\text { Total risk } \\
\text { score } \\
T_{i}\end{array}$ \\
\hline $\mathbf{1 .}$ & $R_{1}$ & 0.123 & 738.81 & 91.211 \\
\hline $\mathbf{2 .}$ & $R_{2}$ & 0.395 & 1638.59 & 647.344 \\
\hline $\mathbf{3 .}$ & $R_{3}$ & 0.185 & 919.00 & 170.185 \\
\hline $\mathbf{4 .}$ & $R_{4}$ & 0.297 & 876.56 & 260.338 \\
\hline & TOTAL & 1.000 & 4172.96 & - \\
\hline
\end{tabular}




\section{Risks ranking}

Taking into account the data from table no.

3 , we may forward the following risks

hierarchy:

Table 3 Risks hierarchy depending on score (source: author's conception and processing)

\begin{tabular}{|c|c|c|c|c|c|}
\hline No. & Risk definition & Symbol & $\begin{array}{c}\text { Total risk } \\
\text { score } \\
T_{i}\end{array}$ & Ranking & $\begin{array}{l}\text { Risk } \\
\text { grade }\end{array}$ \\
\hline 1. & $\begin{array}{l}\text { Conditioning the purchase on } \\
\text { the acquisition of a minimum } \\
\text { imposed quantity }\end{array}$ & $R_{4}$ & 260,338 & 2 & $\begin{array}{l}\text { Medium } \\
\text { risk }\end{array}$ \\
\hline 2. & $\begin{array}{l}\text { Unreal character of the stocks } \\
\text { displayed in SEAP }\end{array}$ & $R_{2}$ & 647,344 & 1 & High risk \\
\hline 3. & $\begin{array}{l}\text { Relatively low price of product } \\
\text { doubled by a small quantitative } \\
\text { demand }\end{array}$ & $R_{3}$ & 170,185 & 3 & $\begin{array}{l}\text { Moderate } \\
\text { risk }\end{array}$ \\
\hline 4. & $\begin{array}{l}\text { Writing down inaccurate data } \\
\text { in the necessary report }\end{array}$ & $R_{1}$ & 91,211 & 4 & Low risk \\
\hline \multicolumn{3}{|c|}{$\begin{array}{l}\text { From table no. } 3 \text { it results that, depending } \\
\text { on the values of the total risk scores, the } \\
\text { hospital top management should beware the } \\
\text { most the unreal character of the stocks } \\
\text { displayed in SEAP by offerors }\left(R_{2}\right) \text {, and } \\
\text { the least the writing down of inaccurate } \\
\text { data in the necessary report }\left(R_{1}\right) \text {. } \\
\text { Although the risk ranking depending on }\end{array}$} & Psm & Pse & \\
\hline
\end{tabular}

their total scores takes into account the risk materialisation, it does not take into consideration all the economic and social market realities and it may be strongly influenced by (unexpected) „black swan” events, with low probability of occurrence, but with very powerful economic consequences. That is why it would be accurate to temperate these types of events by an approache which should not rely on absolute values, but only on relative values. By configuring the statistic-mathematic probability fields (Psm) and the statisticeconomic probability fields ( $P s e$ ) by two squares, and taking into account they are mutually conditioned, we should obtain a diagram of the following type:

Figure no. 1. The relations between the two probability fields (source: author's conception and processing)

The diagram above reflects the inclusiveorder relation between the two fields, the Pse field being included in the other. In other words, risks with Psm probability may occur which are not materialised into economic consequences.

A somewhat graphic vision on the ensemble may lead to a better understanding of the phenomenon. Let's suppose that the danger of risk occurrence represents a ,yellow code”. In this case the entire large square Psm shall be coloured in yellow. We shall consider that the danger of risks materialisation, transformed into damage, should be represented by a ,red 
code", and thus the small square Pse shall be coloured in red. Keeping in mind however the overlapping of the two squares, an ,orange code" results for the Pse square. If we transpose the plastic vision above into statistic-mathematic terms, the actual risk is the result of the overlapping of risk occurrence with the materialisation one. The real index of actual risk occurrence will be highlighted by the product of multiplication of the statisticmathematic probability by the statisticeconomic probability; it is what statistics calls aggregated probability $(P a)$ :

$P a=P s m * P s e$

The calculation of the aggregate probability is shown in the table below. In accordance with its value, we may establish the accurate and actual hierarchy of risks.

Table 4 Calculation of the risk aggregate probability (source: author's conception and processing)

\begin{tabular}{|c|c|c|c|c|}
\hline No. & Risk symbol & $P_{s m_{i}}$ & $P_{s e_{i}}$ & $P_{a_{i}}$ \\
\hline 1. & $R_{1}$ & 0.123 & 0.177 & 0.0218 \\
\hline 2. & $R_{2}$ & 0.395 & 0.393 & 0.1552 \\
\hline 3. & $R_{3}$ & 0.185 & 0.220 & 0.0407 \\
\hline 4. & $R_{4}$ & 0.297 & 0.210 & 0.0624 \\
\hline \multicolumn{2}{|r|}{ TOTAL } & 1.000 & 1.000 & - \\
\hline
\end{tabular}

The use of this criterion is much more appropriate for risk ranking, because it takes into account the sequence of events and, as far as possible, it ,dilutes" into the multitude the extraordinary events from the „black swan” category.

Depending on the aggregate probability or

the aggregate coefficient, the hierarchy does not change, because the Pse weights observe the hierarchy of absolute values of additional expenditure resulted from the materialisation of risks in this total expenditure.

Actually, the hierarchy remains the same, as we can see in the table below:

Table 5 Risk hierarchy depending on the aggregated probability (source: author's conception and

\begin{tabular}{|c|l|c|c|c|c|}
\hline No. & \multicolumn{1}{|c|}{ Risk definition } & Symbol & $P a$ Value & Rank & Risk grade \\
\hline 1. & $\begin{array}{l}\text { Unreal character of the } \\
\text { stocks displayed in SEAP }\end{array}$ & $R_{2}$ & 0.1552 & 1 & High risk \\
\hline 2. & $\begin{array}{l}\text { Conditioning the purchase } \\
\text { on the acquisition of a } \\
\text { minimum imposed quantity }\end{array}$ & $R_{4}$ & 0.0624 & 2 & $\begin{array}{c}\text { Medium } \\
\text { risk }\end{array}$ \\
\hline 3. & $\begin{array}{l}\text { Relatively low price of } \\
\text { product doubled by a small } \\
\text { quantitative demand }\end{array}$ & $R_{3}$ & 0.0407 & 3 & $\begin{array}{c}\text { Moderate } \\
\text { risk }\end{array}$ \\
\hline 4. & $\begin{array}{l}\text { Writing down inaccurate } \\
\text { data in the necessary report }\end{array}$ & $R_{1}$ & 0.0217 & 4 & Low risk \\
\hline \multicolumn{2}{|c|}{ TOTAL } & 1.000 & 1.000 & - & \\
\hline
\end{tabular}

\section{Conclusions}

Taking into consideration the analysis conducted, we may conclude that one may identify and separate the causes of risks of a direct acquisition made in the Electronic System of Public Acquisitions, and the 
extent to which they may influence the consequences can be measured.

Obviously, for the elaboration of factorialcausal econometric models we may take into account three relations, two certain and one uncertain, as follows:

$T=P s m * V e$ (certain relation);

$P a=P s m *$ Pse (certain relation);

$P s e=f(P s m)$ (uncertain relation).

The first two relations are classic, of factorial dependences, and can be investigated under several aspects (dynamic, for instance), highlighting the contribution of each factor in the global evolution of the direct acquisition phenomenon. In search of the connection between two or several variables, it is only natural to start from the hypothesis of a linear dependency, because linearity is usually the most frequently form remarked in the environment, and within the socialeconomic phenomena. Nevertheless, independently from the dependency form, there will always be two factors:

Psm (statistic-mathematicprobability):

independent factor, cause;

Pse ( statistic-economic probability): factor depending on the prior factor, effect.

From the standpoint of informational content, the third relation may be considered much more relevant and useful.

\section{References}

[1] Munteanu Victor, Internal audit in public enterprises and institutions (in original in Romanian), Wolters Kluwer Ed., March 2010.

[2] Dascălu Elena Doina, Nicolae Florina, Internal audit in public institutions (in original in Romanian), Economic Publishing House, January 2006.

[3] Voina Cristina Maria, Internal audit between theory and practice (in original in Romanian), Pro Universitaria Press, Ave Science collection, October 2016. 